\title{
TIPOLOGÍA DEL RELATO DE VIAJES EN LA LITERATURA HISPANOAMERICANA: DEFINICIONES Y DESARROLLO
}

\author{
FEDERICO GuZMÁn Rubio \\ Becario CONACYT (México)-UAM
}

\section{RESUMEN}

Pese a ser uno de los géneros con mayor tradición en la historia de la literatura, el relato de viajes distaba mucho de contar con una poética definida. En el orbe hispánico, esta situación ha cambiado radicalmente gracias a las investigaciones recientes de Carrizo Rueda y de Alburquerque, entre otros especialistas. Partiendo de sus definiciones del relato de viajes, que permiten emprender una selección de textos basada en criterios retóricos, narratológicos y culturales, y no sólo temáticos, como tradicionalmente se acostumbraba, este trabajo explora el desarrollo del género en la literatura hispanoamericana desde la Independencia e intenta describir los diversos patrones formales en que se ha plasmado, los cuales también han experimentado su propia evolución. La tipología esbozada da cuenta de submodelos que pueden extrapolarse a otras literaturas.

Palabras clave: Literatura hispanoamericana. Relato de viajes. Poética. Cronología. Tipología.

\section{LATIN AMERICAN TRAVEL ACCOUNTS TYPOLOGY: DEFINITIONS AND DEVELOPMENT}

\begin{abstract}
Although travel accounts are one of literary genres with more tradition in literature, their poetic was far beyond of being well defined. Thanks to Alburquerque and Carrizo Rueda researches, among others, this situation has radically changed in the Hispanic world. From their definitions of travel accounts, that allow selecting texts by narratological, rhetoric and cultural criteria, not only focusing on the subject, as traditionally was done, this work explores the genre development in Latin American literature since Independence with the purpose of explaining its chronological development. It also tries to describe the different formal patterns in which the genre has been practiced, all of which has also suffered its own evolution. The suggested typology is formed by models that can be extrapolated to other literatures.
\end{abstract}

Key Words: Latin American Literature. Travel accounts. Poetics. Chronology. Typology. 
Hasta hace pocos años, el estudio del relato de viajes hispanoamericano presentaba dos problemas, que se han subsanado en buena medida: (i) la falta de un marco teórico que sustentara y posibilitara el estudio de los textos y (ii) el interés preponderante de la crítica por los relatos de viajes escritos sobre América Latina, en detrimento de los producidos desde ese contexto. Gracias a los avances aportados por la teoría literaria en relación con el género, actualmente es posible abordar su variante hispanoamericana con nuevas herramientas críticas, lo que, aunado al interés por rescatar esta tradición literaria relativamente ignorada, permite delimitar un corpus de relatos de viajes y proceder a su estudio.

El objetivo del presente trabajo se orienta hacia esa dirección. Una vez establecida una definición del género, como se ha señalado, queda por rastrear y señalar qué textos pueden incluirse en él. Esta labor, aparentemente sencilla, se complica en el caso del relato de viajes, dada su naturaleza esquiva. Por tal motivo, es necesario fijar la atención en los subgéneros, submodelos o 'moldes' en los que el relato de viajes se ha plasmado en la literatura hispanoamericana, con un doble fin: delimitar las formas en que aparece en dicha literatura e identificar algunos de los submodelos del relato de viajes moderno.

\section{EL RELATO DE VIAJE Y SUS 'SUBMODELOS'}

A pesar de que el relato de viajes es un género literario practicado ininterrumpidamente desde la antigüedad clásica hasta nuestros días, fue hasta hace pocos años cuando, al menos en el ámbito hispánico, se ha buscado definirlo con rigor académico. No es materia del presente trabajo entrar en los debates que la cuestión ha levantado, sino, al contrario, aprovechar sus hallazgos para proponer una taxonomía. Una definición apropiada es la que propone Alburquerque (2006: 86):

En resumen, podríamos concluir que el género consiste en un discurso que se modula con motivo de un viaje (con sus correspondientes marcas de itinerario, cronología y lugares) y cuya narración queda subordinada a la intención descriptiva que se expone en relación con las expectativas socioculturales de la sociedad en que se inscribe. Suele adoptar la primera persona (a veces, la tercera), que nos remite siempre a la figura del autor y parece acompañada de ciertas figuras literarias que, no siendo exclusivas del género, sí al menos lo determinan. Está fuera de toda duda que los límites de este género no cuentan con perfiles nítidos.

Ceñirnos a esta definición, establecida de acuerdo con una revisión del relato de viajes en la literatura hispánica, nos permite acotar la materia de estudio siguiendo pautas narratológicas, culturales y retóricas, y no sólo temáticas, como tradicionalmente se venía haciendo. De esta forma quedan excluidas de la definición de Alburquerque, y del corpus analizado en el 
presente trabajo, las obras ficcionales que tratan el tema del viaje y que han recibido una merecida atención crítica, dada su relevancia literaria.

No obstante, la variedad de tipos de textos que se podrían enmarcar en la definición de Alburquerque sigue siendo muy amplia y variada, como él mismo advierte al señalar que «los límites de este género no cuentan con perfiles nítidos». Este hecho ya había sido remarcado por Carrizo Rueda (1997: 179) al proponer su propio modelo — tomado como base por Alburquerque-, después de demostrar que la poética específica del relato de viajes existe: «[...] ese mismo modelo se expresa para amoldarse a cada situación concreta, al ir integrando las variables dejadas de lado en distintos casos y se perfilan así con toda su operatividad, los submodelos». No es extraño que el género haya evolucionado y se haya adaptado a las particularidades de cada época y geografía, más aún si tomamos en cuenta que es posible rastrear relatos de viajes en prácticamente todos los periodos de la literatura occidental. Además, parte de su interés literario radica en la variedad de submodelos — como los llama Carrizo Rueda- en que se puede plasmar, y quizás esta capacidad de transformación explique su perdurabilidad, aunada al hecho de que expresa una experiencia, la del viaje, que es inherente al ser humano.

Otra estudiosa del género, Almarcegui (2008: 27), resalta el hecho de que la variedad de formatos en que aparece el relato de viajes dificulta su definición:

La versatilidad del desplazamiento asegura cierta libertad formal, pero también un género huidizo que se resiste a la descripción. Y la variedad de textos susceptibles de entrar en la literatura de viajes dificulta la tipología. De allí que durante mucho tiempo el género se articule a una simple taxonomía de sus contenidos.

Es justamente por este motivo por el que consideramos que fijar los formatos «susceptibles de entrar en la literatura de viajes» enriquecerá el conocimiento sobre el género; al hacerlo a partir de la definición de Alburquerque, se contará con sostén teórico sólido y, a la postre, también demostrará la utilidad y pertinencia de la citada definición.

La dificultad para definir el género debido a la variedad de tipos de textos que lo conforman tampoco ha pasado desapercibida para Peñate (2004: 18-19), quien, a partir de la lectura de Pasquali, un teórico francés, advierte:

Pasquali precisa una parte del problema [de la definición del género] destacando que uno de los rasgos distintivos del relato de viaje es su capacidad de acoger a una gran diversidad de géneros y tipos discursivos incluso sin homogenizarlos, sin diluirlos, dejándolos en su estado previo, lo cual puede generar una sensación de materiales superpuestos sin un proyecto de composición. Pero a su vez, el relato puede incorporarse a textos del más diverso tipo: epistolares, autobiográficos, etnográficos (el célebre Tristes trópicos de Lévi-Strauss), etc., planteando 
así problemas como su misma localización, su relación con el texto que lo alberga y con las instituciones literarias, entre otros.

Peñate señala una de las características que más dificulta la definición e incluso la ubicación del relato de viaje: la capacidad de absorber diferentes tipos de discursos y géneros y, a la vez, la posibilidad de enquistarse en otro texto, convirtiéndolo total o parcialmente en un relato de viaje. Resulta difícil pensar en otro género literario con tan clara capacidad de absorción y maleabilidad: la novela admite toda clase de discursos pero no puede insertarse en un texto más amplio; el cuento, por el contrario, puede incorporarse a otros géneros, pero su poética demasiado estricta y su extensión breve le impiden albergar textos con cierta autonomía. Una notable excepción es la de la crónica literaria, que, como se verá más adelante, está estrechamente relacionada con el relato de viaje, con el que incluso puede llegar a (con)fundirse.

Ante la inquietud académica frente a la versatilidad del género, se hace necesario recurrir a ejemplos concretos e intentar señalar nuevas tipologías. Uno de los propósitos de esta tarea es facilitar la ubicación de los relatos de viaje en la historia literaria y en la literatura de viajes de la actualidad - recordemos que el género muestra un vigor que entusiasma. La falta de interés históricamente advertida en relación con el relato de viajes hispanoamericano dificulta la tarea, pero también la hace aún más necesaria.

Encontrar puntos de contacto entre relatos que hasta ahora se han estudiado de manera aislada no es labor sencilla. Esta situación ya fue planteada por Carrión (2005: 56), quien apunta a la necesidad de rastrear los relatos para, entre otras tareas pendientes, establecer la relación que guardan entre sí y evaluar si realmente existe una tradición de escritura de viajes hispanoamericana ${ }^{1}$ :

Aún hoy en día las obras viajeras del argentino Domingo Sarmiento, del español exiliado en Gran Bretaña Blanco White, del argentino radicado en París Edgardo Cozarinsky o del español afincado en Marruecos Juan Goytisolo constituyen piezas sueltas, no una tradición literaria. Aunque seguramente no sea tan abundante como la anglosajona, sospecho que existe esa estela de autores, que todavía no es considerada en su continuidad [...] Pero sí intuyo que los hilos son más de los que parecen. Habría que rastrearlos.

\footnotetext{
${ }^{1}$ Carrión ubica a la literatura hispánica de ambos lados del Atlántico dentro de una misma tradición. Aunque concordamos con él, en el presente trabajo no se estudian relatos españoles por rebasar los objetivos planteados. Por otra parte, en lo referente exclusivamente al relato de viajes resulta interesante conservar la dicotomía Hispanoamérica/España porque una parte sustancial del relato de viajes en español se ha construido (y se sigue construyendo) a partir de la misma.
} 


\section{LA AUTOBIOGRAFÍA O EL LIBRO DE MEMORIAS}

Si el pacto autobiográfico que se establece entre autor/narrador/protagonista y lector es una de las características definitorias del relato de viajes y de la autobiografía, resulta evidente la estrecha relación que mantienen ambos géneros. En cierta forma, el relato de viajes es una autobiografía limitada al periodo de duración de un periplo, cuya narración se articula siguiendo las pautas de cronología e itinerario que el trayecto determina.

La gran movilidad geográfica que muchos escritores experimentaron contrasta con la supuesta escasez de relatos de viaje hispanoamericanos. Sin embargo, este nomadismo dejó sus marcas en la escritura autobiográfica, que bien podría leerse poniendo más atención en el tema del viaje. Molloy (1991: 222-223), en su ensayo dedicado a la escritura autobiográfica en Hispanoamérica, repara en ello:

El desplazamiento geográfico, a menudo artístico, marca muchas vidas en Hispa-
noamérica. [...] El autobiógrafo se traslada: de la provincia a la capital, de su país
a otro país, de un continente a otro continente. [...] El gastado cliché que equipara
la vida con el viaje adquiere, en la autobiografía hispanoamericana, plena literalidad.

Si se acepta la correspondencia entre ambos géneros es posible establecer al menos tres modelos de vinculación: la mezcla total entre la autobiografía y el relato de viaje; la circunscripción de la autobiografía a un único viaje, aunque abarque un periodo relativamente amplio; y la inclusión, en la narración de toda una vida, de uno o varios fragmentos dotados de unidad destinados a contar las peripecias del viaje.

Un ejemplo paradigmático del primer caso son las Memorias (1865) de fray Servando Teresa de $\mathrm{Mier}^{2}$. Como es sabido, dicho libro está compuesto por diferentes escritos que redactó el padre Mier desde los calabozos de la Inquisición en 1819, y que vieron la luz medio siglo después. Los diferentes títulos que ha recibido la obra brindan una buena idea de la relación estrechísima entre vida y viaje tanto en sus páginas como en la biografía del patriota mexicano.

El padre Mier, naturalmente, tituló de manera independiente cada uno de los textos que redactó y que después fueron recopilados en un solo volumen. El más extenso y el más interesante para nuestros fines es la Relación de lo que sucedió en Europa al doctor Mier, título que hace hincapié en el viaje. Manuel Payno —otro escritor viajero-, responsable de la primera edición del padre Mier, decidió titularla Vida, aventuras, escritos y viages. Sin embargo, el título que prevaleció fue el de Memorias, establecido por Alfonso Reyes en su edición de 1917, en la que publicó

\footnotetext{
${ }^{2} \mathrm{Al}$ lado de todos los relatos citados se incluye la fecha de su primera publicación.
} 
de forma integral la Relación y la Apología del doctor Mier, versión detallada del proceso que sufrió Mier y de su defensa ante los cargos que se le imputaron. En sucesivas ediciones de las Memorias se han ido añadiendo nuevos textos, casi siempre relacionados con el viaje, como aquellos en los que narra su estancia en Londres o la expedición independentista que organizó junto a Francisco Xavier Mina.

El viaje tiene tanta importancia en la obra de Mier que acabó confundiéndose con su autobiografía. Sin pretenderlo, inaugura dos vertientes que marcarían en buena medida el relato de viaje hispanoamericano: la del viajero exiliado y la del viajero ultracrítico de España.

Aunque el relato suele explayarse en aspectos judiciales, esto no impide que se aborden también todo tipo de cuestiones, tal y como es característico del género. El padre Mier encuentra la ocasión para la crítica del clero, en particular de su orden, los dominicos; describe las costumbres religiosas, la política, la moda de París ${ }^{3}$; menciona las principales librerías de Madrid y de vez en cuando, aprovechando la libertad formal característica del relato de viaje, introduce poemas de su autoría. Su periplo no responde al simple turismo, sino que empieza como un exilio y se convierte en una huida constante, lo que le confiere un cariz novelesco. Al ir describiendo sus constantes fugas, el viaje se acelera cada vez más. Al final, el padre Mier (2006: 187) resume con una frase exacta su estancia en España y la forma en que cierto viajero literario vive y describe un país o una región: «Pero yo no he aprendido la topografía de España sino a golpes y palos».

Más de un siglo después, en otro viaje por España, Elena Garro escribió un libro que hace patente la relación existente entre los relatos de memorias y los de viajes: Memorias de España, 1937 (1992). En él existe un equilibrio entre las vivencias de la escritora y la realidad que describe, lo que, en mayor o menor medida, caracteriza a un relato de viajes. Además de su valor literario, este texto resulta interesante por la información biográfica que nos aporta de Garro, sobre un lapso breve pero definitorio de su vida, así como por la recreación de un periodo dramático de la historia y de la cultura de España.

El libro es un recuerdo de viaje por la España republicana y, sobre todo, un fresco de la vida intelectual durante la Guerra Civil. Se inicia, siguiendo la estructura típica de los relatos de viaje, con los preparativos de la travesía que llevaría al matrimonio Paz Garro a España, y concluye con su regreso a México. Garro intercala sin ningún problema episodios bélicos con descripciones de cenas fastuosas, debates intelectuales con co-

\footnotetext{
${ }^{3}$ Resulta interesante que el padre Mier (2006: 83) se fije más en detalles de la vida cotidiana o en las noticias del momento que en datos más enciclopédicos; él mismo advierte: «Se extrañará que deje a París sin decir nada de la ciudad en general, de su población, ni de la Francia. Esto pertenece a la estadística o la geografía, y hay libros donde estudiarla».
} 
mentarios sobre la moda de entonces, y se las arregla para pasar hambre y cenar con embajadores, cortejar con espías soviéticos y rescatar a intelectuales en apuros, dormir en el legendario Hotel Victoria de la madrileña Plaza Santa Ana y en cabinas de barco de tercera clase o en tiendas militares.

Desde el punto de vista documental, el libro resulta muy rico, y desde un punto de vista estrictamente literario, su valía es indiscutible; sorprende, además, el número de registros presentes en sus breves páginas, que van del humor y la picardía a la nostalgia y la frivolidad. Al finalizarlo, el lector puede afirmar con igual certeza que leyó un fragmento de la autobiografía de Garro y que, al mismo tiempo, leyó un relato de viaje en toda regla.

Hay, en cambio, autobiografías salpicadas de numerosos viajes. Tal es el caso de Confieso que he vivido (1974), en la que Neruda cuenta su vida enfatizando su vocación poética, su actividad política, su historia sentimental, las personalidades que conoció y, por supuesto, sus múltiples viajes. Las memorias de Neruda están, en parte, estructuradas de acuerdo con esos periplos, como se comprueba a partir de los títulos de algunos capítulos: «Los caminos del mundo», «España en el corazón» o «México florido y espinudo». Neruda viajó sin cesar desde que salió de Chile a los veintidós años para ocupar el cargo de cónsul ad honórem en Birmania. Además de América Latina y Europa, conoció regiones y países poco frecuentados por sus contemporáneos, como Birmania, la Unión Soviética o la China comunista. Confieso que he vivido contiene muchos relatos de viaje perfectamente autónomos y, tanto el libro como la vida del poeta, pueden leerse como la unión de todos ellos. Sorprende, por tal motivo, que Neruda (1974: 235), quien pasó la mayor parte de la vida fuera de su tierra natal, escribiera:

Pienso que el hombre debe vivir en su patria y creo que el desarraigo de los seres humanos es una frustración que de alguna manera u otra entorpece la claridad del alma. Yo no puedo vivir sino en mi propia tierra; no puedo vivir sin poner los pies, las manos y el oído en ella, sin sentir la circulación de sus aguas y de sus sombras, sin sentir cómo mis raíces buscan en su légamo las substancias maternas.

\section{LOS DIARIOS}

La escritura diarística, por su intención de contar vivencias reales, es una variante de la autobiográfica. Lo que la diferencia de esta es su pretensión de simultaneidad y un mayor apego a la verdad, puesto que las entradas de un diario no se consignan como una evocación lejana, sino poco tiempo después de que los hechos hayan ocurrido. Otro rasgo que sobresale de los diarios es su precisión cronológica y su delimitación temporal exacta, consecuencia de la anotación de la fecha en cada entrada. Aunque 
existen diarios que abarcan prácticamente toda una vida, su escritura suele comprender periodos precisos.

En los diarios que agrupan varios años es posible extraer las entradas relativas a un viaje, que forman un conjunto con plena autonomía. Aunque los ejemplos no abundan en la literatura latinoamericana, se han publicado algunos volúmenes que siguen este patrón, como Unos días en Brasil: Diario de viaje (1991) de Adolfo Bioy Casares. Más numerosos son los casos en los que la totalidad del diario se ajusta a un viaje y, de hecho, resulta posible identificar un subgénero bien delimitado: el diario de viaje ${ }^{4}$. Al igual que en la autobiografía, este subgénero nació en la América Latina republicana de la mano de uno de uno de los héroes de la independencia, el venezolano Francisco de Miranda.

Miranda consignó cuidadosamente los pormenores de su agitada vida en un archivo que alcanzó los sesenta y tres tomos, y que llevaba consigo adonde fuera. De ese archivo proceden sus tres diarios de viaje más conocidos y bastante diferentes: Viaje por los Estados Unidos de la América del Norte, Viaje por Italia y Viajes por Rusia (1977).

En el primero predominan las acciones sobre las descripciones; Miranda visita, camina, pasea, lee y conoce personalidades, monumentos y ciudades sin entrar en mayores detalles. Todos los aspectos de Estados Unidos, país que admira y que marcará su anglofilia, le llaman la atención: las ciudades, el ganado, la agricultura, la religión, las vías de comunicación, la industria, las instalaciones militares. Así como fray Servando inauguró la tradición del viajero latinoamericano exiliado, Miranda inaugura la del viajero político que es recibido por las personalidades más importantes, no repara en limitaciones económicas e imprime siempre un carácter utilitario al viaje; en este caso, el de observar el espectáculo de un país que nace y compararlo, con bastante objetividad, con la realidad de su América.

En el viaje a Italia se pierde el entusiasmo de los Estados Unidos y lo que en el diario anterior era una sucesión de acciones se convierte en una enumeración de palacios y obras de arte. Miranda parece viajar a Italia, admirar sus monumentos y manifestar su sorpresa por obligación, como un mero trámite para inscribirse en la tradición de su tiempo.

Por último, en Rusia se abandona a las amabilidades con las que es recibido, que le hacen obviar la tiranía política del país, actitud que el lector esperaría en un viajero libertario e idealista como Miranda. Es en este diario donde se encuentran las descripciones más pormenorizadas, casi siempre acentuando la imagen positiva que el imperio le despierta.

\footnotetext{
${ }^{4}$ Si se acepta la hipótesis según la cual la literatura latinoamérica se inicia con las crónicas de Indias, entonces su libro fundador sería un diario de viaje, el Diario de a bordo, de Cristóbal Colón.
} 
El interés de los diarios de Miranda no solo reside en la importancia histórica de su autor, sino en que constituyen uno de los primeros testimonios de la observación del mundo desde una perspectiva latinoamericana. Además, a pesar de los desequilibrios ya señalados, sus diarios cuentan y describen al sujeto enunciador y a la sociedad analizada, como puede apreciarse en el siguiente párrafo dedicado a Venecia en el Viaje por Italia (1977: 205 y 206):

Temprano fue menester dar una paliza al criado, que tuvo la insolencia de quererme gobernar, diciendo a una moza que vino a buscarme, que yo no estaba en casa, porque esta no le quiso dar dineros; mas se engañó el picarón, y llevó sus muy buenos palos a cuenta... es increíble la sumisión y respeto con que desde entonces me sirven todos en la casa... o infelices, que es necesario trataros mal para que sirváis bien! - a las 11 estuve a hacer una visita a Zaguri, que aún estaba en la cama: allí se peinan, y reciben gentes hasta las 12 que se levantan para ir al Senado... luego a las Put... después al Theatro; y así del theatro al bordel, y del bordel al theatro pasan la vida - tomamos café (que es el uso a todas horas del día) y yo me fui a recorrer algunos Palacios con mi nuevo Cicerone. Primo al Palazzo Barbadigo de la Talasa, a S. Polo; aquí estaba la escuela del Tiziano; y entre los cuadros que allí se conservan de este ilustre artista, resaltan un Venere: la Madalena: y una Ninfa e Satiro, excelentes Piezas.

Un viaje opuesto en todos sentidos al de Miranda fue el que emprendió Horacio Quiroga a París en 1900, en pleno auge del modernismo latinoamericano. Aunque el objetivo del viaje no queda claro, el diario da a entender que el uruguayo pretendía convertirse en cronista de viajes y experimentar la bohemia parisiense. En todo caso, el diario no fue escrito para publicarse, y vio la luz póstumamente, cincuenta años después de ser escrito.

Durante los cuatro meses que duró el periplo nada le salió bien a Quiroga: la travesía marítima lo aburrió y decepcionó; dilapidó la pequeña fortuna que llevaba en unas cuantas semanas y se quedó con el dinero justo para comer una vez al día; dejó de bañarse, afeitarse y cortarse el pelo y adquirió un aspecto salvaje; no simpatizó con los poetas modernistas; no logró conocer a los simbolistas franceses; no obtuvo ningún trabajo y solo logró vender un par de crónicas al periódico de Salto, su ciudad; perdió el contacto con Uruguay, por lo que tuvo que postergar su ansiado regreso. Al final de su estancia, Quiroga (1950: 107) se queja: «En cuanto a París, será muy divertido pero yo me aburro. Verdad que no tengo dinero, lo que es algo para no divertirse».

Quiroga es uno de los primeros escritores en explotar el tema de la marginalidad del artista latinoamericano en Europa, que también encontramos en los diarios de Julio Ramón Ribeyro, o en las páginas autobiográficas de Bryce Echenique. Además, en El diario de Horacio Quiroga a París (1950) sobresale un aspecto presente en varios relatos de viajes: la transformación del viajero. Quiroga se embarca en el viaje de ida escri- 
biendo poemas modernistas y se registra en el barco como «comerciante», pero regresa como «periodista», para abandonar la poesía y escribir cuentos realistas. Sin saberlo, con el fracaso absoluto de su viaje, el escritor se adscribe a una tradición latinoamericana replegada sobre sí misma, más afecta a escribir sobre la rudeza de las selvas del continente que sobre los encantos de Europa. El modelo opuesto de escritor lo encarna el guatemalteco Enrique Gómez Carrillo, exitoso y cosmopolita, con quien Quiroga tuvo un serio desencuentro en un café parisino por sus visiones divergentes de lo que debía ser la literatura latinoamericana; la escena, en la que Gómez Carrillo se burla de Quiroga por aprender guaraní mientras él está estudiando el alemán, es uno de los pasajes más interesantes del diario.

Un ejemplo curioso es el Diario de una caraqueña por el Lejano Oriente (1920), publicado por Teresa de la Parra en la revista Actualidades, dirigida por Rómulo Gallegos. El texto, entretenido y agudo, tiene todas las características del diario de viajes; sin embargo, Teresa de la Parra nunca viajó a Oriente, y su diario está basado en las cartas enviadas por su hermana María, la verdadera viajera. Aunque no hay marcas textuales que la hagan patente, la tensión entre ficcionalidad y factualidad, por las circunstancias de escritura del diario, hace de este texto un documento único y cuestiona los pilares en que se sostiene el género. Cuatro años después, la venezolana publicaría su primera novela, Ifigenia, Diario de una señorita que escribió porque se fastidiaba, cuyo subtítulo ya anuncia la forma en que está escrita, por lo que aquel diario apócrifo puede verse como un antecedente importante de su obra novelística.

\section{LAS CARTAS}

El hecho de que Teresa de la Parra haya reescrito las cartas de su hermana y las haya transformado en un diario dice mucho de la concepción que tenía de ambos subgéneros; es posible deducir que de la Parra consideró que, si bien la experiencia que narraban las cartas era interesante, la forma de transmisión no tenía mayor relevancia. Al reescribirlas, les otorga literariedad; convierte un simple testimonio personal en literatura.

En este camino que media entre el simple testimonio personal y la voluntad literaria surge uno de los conflictos más intensos del relato de viajes, sobre todo en las modalidades más ligadas a la escritura autobiográfica: las memorias, los diarios y las cartas. De hecho, sería interesante clasificar estos textos entre los que fueron concebidos para publicarse, en los que podemos suponer una mayor intención literaria, y los que fueron escritos por cualquier otro motivo, aunque esta división no implique de manera inmediata que la literariedad de los del primer grupo sea necesariamente mayor que la de los del segundo. 
Uno de los pocos relatos de viajes incluidos en el canon de la literatura hispanoamericana son los Viajes (1849), de Domingo Faustino Sarmiento. Son numerosos los aspectos literarios e históricos relevantes del texto, pero lo que más nos concierne son las reflexiones que se ofrecen en torno al relato de viajes.

Existe cierto consenso (Rojas, 1996: XXVI) en cuanto a que Sarmiento escribió las cartas que integran los Viajes sin intención de que vieran la luz. No obstante, además del hecho de que las publicó apenas un año después de su regreso a América, en el texto hay varias afirmaciones que permiten discrepar. Sorprende, por ejemplo, la conciencia que Sarmiento (1996: 3) tiene del relato de viajes, al que para empezar le otorga el estatus de género literario, por lo que resulta plausible pensar que deseaba que su obra se inscribiera en este campo de la literatura. Por si fuera poco, señala algunas características genéricas que llaman hoy en día la atención de la crítica, como la relación entre relato factual y ficcional, y menciona a Dumas, con lo que respeta la tradición de rememorar a algunos de los clásicos que antecedieron al viajero que escribe:

Las impresiones de viaje, tan en voga como lectura amena, han sido explotadas por plumas como la del creador inimitable del jénero, el popular Dumas, quien con la privilejiada facundia de su espíritu, ha revestido de colores vivaces todo lo que ha caido bajo su inspección, hermoseando sus acontecimientos dramáticos o novedosos ocurridos muchos años ántes a otros, i conservados por la tradición local; a punto de no saberse si lo que se lee es una novela caprichosa o un viaje real sobre un punto edénico de la tierra.

A pesar de que las cartas tienen diferentes destinatarios, el estilo del volumen es bastante homogéneo, lo que hace sospechar que Sarmiento siempre barajó la idea de estar creando una obra unitaria. Además, las cartas se suceden respetando la cronología del viaje, resultado, seguramente, de una selección y estructuración cuidadosa. Ahora bien, si Sarmiento pretendía escribir un libro de viajes, quedaría la duda de por qué eligió el formato epistolar. Él mismo nos brinda la respuesta (Sarmiento 1996: 5) al afirmar: «el andar abandonado de la carta, que tan bien cuadra con la natural variedad del viaje».

$\mathrm{Si}$ bien en su recorrido varias veces se muestra acomplejado por la tradición y el progreso europeo, en contraste con la juventud y atraso de América Latina, esgrime su condición de viajero para contrarrestar esta supuesta inferioridad: «i puedo envanecerme de haber sentido moverse bajo mis plantas el suelo de las ideas, i de haber escuchado rumores sordos, que los mismos que habitaban el pais, no alcanzaban a apercibir» (Sarmiento 1996: 5).

No hay que olvidar que Sarmiento es a la vez un viajero intelectual y político, lo que, más que limitar su mirada, la amplifica. Si Miranda lo antecede al establecer la figura del político latinoamericano de viaje, Sar- 
miento puede ser visto, más por su importancia que por un respeto estricto de la cronología, como el modelo del viajero intelectual latinoamericano. En este sentido, uno de sus herederos más célebres, que también eligió las epístolas para narrar su periplo europeo, fue el peruano José Carlos Mariátegui, quien en sus Cartas de Italia (1969) expresa sus ideas políticas de izquierda.

Un viajero singular, quizás por tratarse de un simple turista, es Adolfo Bioy Casares. El argentino envió desde Europa una serie de cartas a Silvina Ocampo, su esposa, y a su hija, en las que cuenta el viaje de cuatro meses por Francia, Inglaterra, Escocia, Suiza y Alemania. Las cartas, que se publicaron treinta años después con el título de En viaje (1967) (1996), parecen haberse escrito sin mayores pretensiones literarias. Las referencias personales son muy abundantes y se suele hacer hincapié más en cuestiones de índole familiar, como el estado de salud o los encargos, que en la descripción de los lugares que se recorren. No cabe duda de que En viaje (1967) constituye una obra secundaria de Bioy, y su interés estriba en reconocer ciertos temas e inquietudes tratados en sus novelas y cuentos y, en algunos pasajes, en la presencia de algunas de las características definitorias de su literatura: el humor, la cortesía hacia el lector, el optimismo, la capacidad de sorprenderse, la concepción del mundo como un conjunto de mundos infinitos, el gusto por la sentencia, las reflexiones sobre el paso del tiempo o la invención de tramas fantásticas.

\section{LA CRÓNICA}

De todos los formatos en que el relato de viajes es susceptible de aparecer, el más privilegiado por la literatura hispanoamericana ha sido la crónica. De hecho, resulta frecuente que al relato de viajes se le denomine crónica de viajes, lo que, desde nuestro punto de vista, genera confusión, ya que la crónica es un molde más en que se presenta el relato de viajes. Desde su nacimiento en el modernismo, que fue su edad dorada, y también, si existe alguna, la edad dorada del relato de viaje hispanoamericano, la crónica ha estado vinculada al tema del viaje y lo sigue estando en la actualidad.

Aunque algunas veces se pasa por alto, la prosa literaria del modernismo fue muy abundante y resulta esencial para entender el surgimiento y el desarrollo de esta corriente estética. De los géneros en prosa, el predominante fue la crónica. La mayor parte de los miembros destacados del movimiento, de los precursores Manuel Gutiérrez Nájera y José Martí, a los últimos modernistas, como José Juan Tablada o José Enrique Rodó, la practicaron.

A los nombres ya citados se pueden agregar los de Julián del Casal, Manuel Díaz Rodríguez, Manuel Ugarte, Amado Nervo y Luis G. Urbina. Mención especial merecen dos figuras. La primera es la de Enrique Gómez 
Carrillo, relativamente olvidado hoy en día, pero que fue en la época uno de los escritores más respetados e influyentes, y que fungió como director de dos de las revistas modernistas por excelencia, El Nuevo Mercurio y Cosmópolis. Prácticamente la totalidad de su obra está constituida por crónicas de viaje que ejercieron gran influencia en sus contemporáneos. Él mismo se encargó de recopilarlas en cerca de veinte títulos. A ojos del lector moderno, las crónicas de Gómez Carrillo parecen frívolas y artificiosas. Quizás el guatemalteco fue una víctima de la retórica de su tiempo, que representó y copió fielmente, lo que le aseguró el éxito en vida; pero cuando declinaron los patrones estéticos bajo los que se regía, su obra perdió toda espontaneidad y marca personal.

Caso contrario es el de Rubén Darío, cuyas crónicas siguen siendo un ejemplo de vitalidad e inteligencia. Su obra está conformada en tres cuartas partes por textos en prosa, pese a lo cual muchas veces se le considera sólo un poeta. Darío publicó en vida seis volúmenes de crónicas de viajes ${ }^{5}$ que se convirtieron en clásicos del género y que sorprenden por su variedad temática, prosa artística y profundidad intelectual.

La profusión de la crónica de viajes se explica por la biografía de sus autores, por algunos de los pilares estéticos e ideológicos del movimiento y por las circunstancias económicas y culturales del momento. Románticos al fin y al cabo, los modernistas aspiraban a una conjunción entre vida y arte, por lo que el viaje no podía restringirse a su aparición como tópico literario, sino que estaban obligados a emprenderlo. Prácticamente todos los escritores modernistas fueron grandes viajeros, y el periplo, en concreto la peregrinación a París, se convirtió en un común denominador. Además, si entre las pautas del modernismo se contaban la búsqueda del cosmopolitismo, el afán de ser y parecer modernos, el gusto por lo exótico, el afrancesamiento y la exaltación del viaje como tema literario, era inevitable que el viaje se convirtiera en una experiencia y modo de vida y que permeara su obra.

El auge de la crónica, que posee todas las características distintivas del relato de viajes, también responde, como señala Rama (1970), a la profesionalización del escritor y a la creación o consolidación de diarios importantes en varias capitales latinoamericanas, como México, Buenos Aires, La Habana, Caracas y Santiago. Los escritores se incorporaron a la escritura periodística por motivos económicos. Sin embargo, como era de esperarse, se sintieron limitados al tener que adaptarse a la prosa convencional y corta de miras propia del periodismo, por lo que crearon una prosa nueva con ambiciones artísticas, y, con ella, un género también novedoso. Gutiérrez

${ }^{5}$ España contemporánea (1901), Peregrinaciones (1901), La caravana pasa (1902), Tierras solares (1904), Parisiana (1907) y El viaje a Nicaragua e Intermezzo tropical (1909). 
Nájera y José Martí, casi simultáneamente, basándose en modelos literarios identificados por González (1983: 69-83), como los chroniqueurs franceses y los artículos de Mariano José de Larra, inauguraron un género en el que el mismo González y otros estudiosos han visto la génesis de la revolución modernista.

Al convertirse la crónica en vehículo de expresión literaria, cada escritor le brinda un toque estilístico personal. Aun así, es posible trazar una trayectoria más o menos definida que corre paralela e incluso antecede a la experimentada por la poesía. En términos generales, como lo ha observado González, en sus inicios, sobre todo en Martí, por ejemplo con «Fiestas de la Estatua de la Libertad» (1886), la crónica estaba más comprometida con las noticias cotidianas, como resultado de su filiación periodística. También, quizás para contraponerse a la prosa periodística chata de esta etapa, en especial la de Gutiérrez Nájera, como en «Crónica color de bitter» (1882), tiende al preciosismo y a la creación de ambientes simbolistas y decadentes; a veces pareciera que el único objetivo de Gutiérrez Nájera es recrear estados de ánimo, generalmente lánguidos. Ya en una segunda etapa, rastreable desde Julián del Casal, y prefigurando otra vez la transformación que sufriría la poesía, la crónica abandona el ímpetu de «el arte por el arte» y la estrecha relación con la noticia y se vuelve más reflexiva, mostrando «a veces solapadamente y a veces abiertamente, una tendencia hacia la teorización literaria» (González, 1983: 175).

No contentos con narrar el objeto de su crónica, los modernistas reflexionan sobre él. Ya no se conforman con contar sus aventuras, por ejemplo, sino que meditan sobre el significado del viaje, como hace Manuel Díaz Rodríguez en «El alma del viajero» (1898), Amado Nervo en «¿Por qué va uno a París?» (1902) y Enrique Gómez Carrillo en «La psicología del viaje» (1913). De hecho, aunque siempre primará la descripción sobre cualquier otro aspecto, la crónica temprana tiende a la narración, incluso algunas crónicas de Gutiérrez Nájera se acercan al cuento, mientras que la tardía se aproxima más al ensayo.

Tras el modernismo, la crónica se vio opacada por la popularidad del cuento y, sobre todo, de la novela. Sin embargo, la crónica de viajes se ha seguido practicando desde entonces y son muchos los autores que han producido textos literarios. Haciendo un rápido repaso se podría mencionar a Alfonso Reyes, Roberto Arlt, César Vallejo, Salvador Novo, Jorge Ibargüengoitia, Guillermo Cabrera Infante o Juan Villoro. Este último (2005: 14) ha analizado las características genéricas de la crónica (no específicamente de la crónica de viajes, pero sus señalamientos se pueden extrapolar al relato de viajes) y comenta que:

Si Alfonso Reyes juzgó que el ensayo era el centauro de los géneros, la crónica reclama un símbolo más complejo: el ornitorrinco de la prosa [...] La crónica es 
un animal cuyo equilibrio biológico depende de no ser como los siete animales [la novela, el reportaje, el cuento, la entrevista, el teatro, el ensayo, la autobiografía] distintos que podría ser.

Para Villoro, la característica distintiva de la crónica es su capacidad para hibridar géneros literarios muy distintos, sin decantarse por ninguno de ellos.

Otra característica de la crónica es su brevedad, condicionada por los medios en que tradicionalmente ha aparecido, antiguamente los periódicos y hoy con mayor frecuencia las revistas. Esta brevedad tiene como consecuencia que, estrictamente hablando, no se narre un desplazamiento, sino más bien una estadía, en general en una ciudad o incluso en un ámbito de una ciudad, como puede ser un monumento, un café o restaurante, un barrio, una calle o un mercado. Champeau (2008) denomina a esta clase de texto «relato de estancia» y aclara que «es una variante del relato de viaje». Esta situación naturalmente resulta problemática para la adscripción de la crónica al relato de viajes, aunque la condición de viajero del narrador y el respeto de todas las particularidades del género despejan cualquier duda. En todo caso, podría afirmarse que en las crónicas de viaje en que no se describen desplazamientos el lector establece un pacto de lectura, aparte del autobiográfico, que consiste en la asunción de que el narrador es un sujeto que no forma parte habitual del paisaje descrito, dada su condición de extranjero o de viajero, lo que le confiere el papel de testigo.

\section{EL RELATO DE VIAJES PROPIAMENTE DICHO}

Recopilar en un volumen crónicas publicadas individualmente en diarios y revistas ha sido una práctica habitual. De hecho, fue el germen de todos los libros de viajes de Rubén Darío. Cuando las crónicas se agrupan siguiendo el itinerario de un viaje (como De Marsella a Tokio (1906) de Enrique Gómez Carrillo) o se recopilan textos dedicados a un solo país o ciudad (como España contemporánea (1901) de Darío), formando un mosaico, el volumen resultante se adscribe a otro formato, el del «relato de viajes propiamente dicho», de acuerdo con Carrizo Rueda (2008: 47). Su principal característica es que el viaje se narra desde los preparativos hasta el regreso, por lo que suele ser más extensos que la crónica. Esta amplitud propicia la inclusión de reflexiones de todo tipo, así como de información histórica y literaria sobre la región que se recorre, e incluso la incorporación de varios tipos de texto, como cartas, poemas, diarios, cuentos, y de elementos paratextuales diversos, como fotografías y mapas.

El ejemplo paradigmático lo constituye Una excursión a los indios ranqueles (1870) del argentino Lucio V. Mansilla, texto que suscita un buen número de discusiones. Mansilla lo publicó a modo de cartas dirigidas a 
su amigo Santiago Arcos, por entregas, en el diario La Tribuna. Esta presentación del relato, que constituyó un simple recurso retórico, muestra la conciencia que tienen los escritores de viajes en cuanto a la maleabilidad del género. El coronel Mansilla, el narrador, expone la excursión que emprendió a los «tolderos» indios con el fin de afianzar un tratado de paz, excusa que le sirve para describir el modo de vida de los indígenas y hacer una descripción casi novelesca de los caciques, los cautivos y sus compañeros de expedición. Sorprende la similitud del relato de Mansilla con las crónicas de Indias; en especial, en lo referente a la curiosidad y el rechazo suscitados ante el otro. En este sentido, el análisis retórico que Alburquerque (2008) desarrolla para mostrar que las crónicas de Indias pertenecen al relato de viajes es perfectamente aplicable al texto de Mansilla.

En contraste, el mexicano Guillermo Prieto no encuentra esa otredad en las excursiones que emprende por su país, recopiladas en Viajes de orden suprema (1858), sino en el vecino del norte, del que dejará su testimonio en Viaje a los Estados Unidos (1877-1878). Prieto primero publicó el Viaje en entregas y posteriormente lo recopiló en tres extensos volúmenes. Como en todos los grandes escritores de viajes, llama la atención su dominio de las reglas del género, que se permite quebrantar y a las que dedica varias reflexiones. En algunos pasajes parodia las aburridas descripciones en las que, según dice, suelen caer este tipo de libros, y, por otra parte, rompiendo una regla básica, incluye un capítulo dedicado a Nueva Inglaterra, pese a no haberla visitado, con el objetivo explícito de que el libro no quedara trunco. Por si fuera poco, Prieto incorpora de manera casi obsesiva toda clase de textos propios y ajenos: poemas, cartas, extractos de libros, titulares de periódicos, litografías e ilustraciones. Muestra del gusto del autor por el juego entre ficcionalidad y factualidad en los libros de viajes es el completamente imaginario Diario de un zuavo (1876), cuya autoría se le atribuye, y que narra las supuestas «impresiones de viajes» de un soldado francés en México.

De 1983 data la publicación de un relato de viaje que parodia magistralmente el género. Se trata de Los autonautas de la cosmopista o Un viaje atemporal París-Marsella (1983), de Julio Cortázar y Carol Dunlop, en el que se cuenta la travesía de treinta y tres días a lo largo de la autopista París-Marsella. El hilo conductor del libro lo constituye un diario de ruta, y entre entrada y entrada se introducen textos de todo tipo (cuentos, fragmentos poéticos, pequeños ensayos, cartas), dibujos y fotografías de la «expedición». Todo el recorrido está planeado con base en los relatos de viaje canónicos, con los que se establece un continuo diálogo y a los que la escritura apela en todo momento. El libro pretende mostrar que la posibilidad del viaje y de su sucesiva escritura siguen existiendo, sin importar que los lugares desconocidos hayan desaparecido y que el turismo se haya masificado. Cortázar y Dunlop (1983: 56) sugieren que la esencia del 
viaje se encuentra en la forma de mirar; para ellos, por ejemplo, la autopista que buscan en su periplo «no solo comporta un espacio físico diferente, sino también otro tiempo». Los autonautas de la cosmopista, tanto por la forma de tratar el tema del viaje como por el destino elegido, constituye el primer relato de viaje posmoderno de la literatura latinoamericana.

\section{RELATOS HÍBRIDOS}

En los últimos años ha surgido una clase de libros que aprovechan la capacidad de apropiación y de enquistamiento del relato de viajes para constituir un molde relativamente novedoso. En realidad, son producto de la radicalización de un recurso ya existente: la creación de textos híbridos.

En términos generales, la hibridación surge de la combinación entre el relato de viajes y el ensayo, hasta el punto de que la adscripción a un género resulta conflictiva. Tal es el caso de La fiesta vigilada (2007), de Antonio José Ponte, en el que se mezclan las reflexiones sobre el exilio, la descripción de los mecanismo de censura del gobierno cubano, la narración de algunos viajes al extranjero y la visión de una Habana en ruinas. En obras del argentino Sergio Chejfec como Mis dos mundos (2008) o Baroni, un viaje (2007), las fronteras entre la novela, el ensayo y el relato de viajes quedan totalmente diluidas.

Esta característica recorre buena parte de la obra de Sergio Pitol, concretamente en los volúmenes que constituyen la Trilogía de la memoria. En uno de ellos, El viaje (2001), se intercalan ensayos sobre literatura rusa en el diario que cuenta el viaje que Pitol emprendió a Moscú y Georgia. A medida que avanza el libro, el lector irá descifrando la profunda relación existente entre los ensayos y el diario, que al principio permanecía oscura. Por el contrario, en Manual del distraído, del venezolano Alejandro Rossi (1980), y en Mil tazas de té (2008), del argentino Luis Chitarroni, es el relato de viajes el que inesperadamente aparece en medio de otro tipo de textos.

\section{CONCLUSIONES}

Aunque desde luego existen géneros literarios mucho más importantes en la literatura hispanoamericana, tanto por la relevancia de las obras como por su número y variedad, el relato de viajes ha sido practicado ininterrumpidamente desde la independencia hasta la actualidad. Existen autores canónicos, como Julio Cortázar, Alfonso Reyes o Pablo Neruda, que plasmaron sus experiencias de viaje en libros que, si bien no constituyen lo más celebrado de su obra, poseen una gran calidad literaria; su lectura resulta necesaria si se desea conocer a fondo a sus creadores. Por otro lado, existen autores impres- 
cindibles en la literatura hispanoamericana cuyas obras más destacadas son relatos de viajes, como Una excursión de los indios ranqueles de Lucio V. Mansilla o la Trilogía de la memoria de Sergio Pitol.

En realidad, resulta imposible hacer un balance del relato de viajes hispanoamericano porque el corpus que lo forma es en buena medida desconocido e incluso algunas de las obras de autores más respetados, como las de Elena Garro o Rubén Darío, no han recibido la atención que merecen en comparación con otros géneros. Sin embargo, la aproximación llevada a cabo permite afirmar que el relato de viaje hispanoamericano es digno de estudio y posee una calidad literaria fuera de toda duda. La versatilidad que presenta a través de sus dos siglos de historia es una muestra de que los autores conocen y manejan sus reglas a fondo y las violan con toda conciencia. Una prueba de este dominio literario es la simple elección del formato que más conviene a lo que desean expresar.

En lo que respecta al género, llama la atención la diversidad de formatos o moldes en los que se presenta, de los cuales hemos localizado y descrito seis: la autobiografía, los diarios, las cartas, la crónica, «el relato de viajes propiamente dicho» y los relatos híbridos. La definición de relato de viajes esbozado por Alburquerque, citada al principio de este trabajo, es perfectamente aplicable a cualquiera de los seis subgéneros, lo que nos habla de un género literario definido con nitidez y a la vez muy maleable. El formato elegido por el autor, paradójicamente, no condiciona el contenido ni el tratamiento del tema, como se aprecia por la gran cantidad de obras heterogéneas, lo que nos permite afirmar que estamos ante uno de los géneros literarios con mayor libertad y variedad formal. Es de esperar que, a la par que la teoría literaria aporta nuevas herramientas de análisis, se rescate y estudie esta vertiente de la literatura hispanoamericana.

\section{REFERENCIAS BIBLIOGRÁFICAS}

ALBURQUERQUE, Luis. «Los 'libros de viaje' como género literario». En: LUCENA GIRALDO, Manuel y Juan PIMENTEL (eds.). Estudios sobre literatura de viajes. Madrid: CSIC, 2006, pp. 67-87.

—. «Apuntes sobre crónicas de Indias y relatos de viajes». Revista de letras (Argentina), 2008, n. ${ }^{\circ}$ 37, pp. 11-23.

ALMARCEGUI, Patricia. «Viaje y literatura elaboración y problemática de un género». Revista de letras (Argentina), 2008, n. ${ }^{\circ} 37$, pp. 25-31.

CARRIÓN, Jorge. «¿Una tradición silenciada? Hacia un corpus de la literatura nómada». Lateral, 2005, n. ${ }^{\circ} 123$, pp. 53-57.

CARRIZO RUEDA, Sofía. Poética del relato de viajes. Kassel: Edition Reichenberg, 1997.

- «El viaje omnipresente. Su funcionalidad discursiva en los relatos culturales de la segunda modernidad». Revista de letras (Argentina), 2008, n. ${ }^{\circ} 37$, pp. 45-56.

CHAMPEAU, Geneviève. «Tiempo y organización del relato en algunos relatos de viaje españoles contemporáneos». En: PEÑATE RIVERO, Julio y Francisco UZCANGA MEINECKE (eds.). El viaje en la literatura hispánica: de Juan Valera a Sergio Pitol. Madrid: Verbum, 2008, pp. 89-103. 
CORTÁZAR, Julio y Carol DUNLOP. Los autonautas de la cosmopista o Un viaje atemporal París-Marsella. Madrid: Alfaguara, (1983), 1996.

GONZÁLEZ, Aníbal. La crónica modernista hispanoamericana. Madrid: Porrúa Terrazas, 1983.

—. «La prosa modernista». En: GONZÁLEZ ECHEVERRÍA, Roberto y Enrique PUPOWALKER (eds.). Historia de la Literatura Hispanoamericana. El siglo XX. Madrid: Gredos, 2006, Tomo II, pp. 95-137.

MIER, Servando Teresa de. Memorias de un fraile mexicano desterrado en Europa. Madrid: Trama, 2006.

MIRANDA, Francisco de. Diario de viajes y escritos políticos. Madrid: Editora Nacional, 1977.

MOLLOY, Sylvia. Acto de presencia: la escritura autobiográfica en Hispanoamérica. México: Colegio de México-Fondo de Cultura Económica, 1991.

NERUDA, Pablo. Confieso que he vivido. Barcelona: Seix-Barral, 1974.

PEÑATE RIVERO Julio. «Camino del viaje hacia la literatura». En: PEÑATE RIVERO, Julio (ed.). Relato de viaje y literaturas hispánicas. Madrid: Visor, 2004, pp. 13-29.

QUIROGA, Horacio. El diario de Horacio Quiroga a París. Montevideo: Talleres Gráficos El Siglo Ilustrado, 1950.

RAMA, Ángel. Rubén Darío y el modernismo: circunstancia socioeconómica de un arte americano. Caracas: Universidad Central, 1970.

ROJAS, Elena M. «Nota filológica preliminar». En: SARMIENTO, Domingo Faustino. Viajes. Madrid: Archivos, 1996, pp. XXVI-XIX.

SARMIENTO, Domingo Faustino. Viajes. Madrid: Archivos, 1996.

VILLORO, Juan. Safari accidental. México: Joaquín Mortiz, 2005.

Fecha de recepción: 1 de julio de 2010

Fecha de aceptación: 16 de diciembre de 2010 